\title{
Left Main Stenting
}

- Now and Future -

\author{
Seung-Jung Park, MD, PhD; Duk-Woo Park, MD, PhD
}

\begin{abstract}
For several decades, based on clinical trials comparing coronary-artery bypass grafting (CABG) with medical therapy, bypass surgery has been regarded as the treatment of choice for patients with unprotected left main coronary artery (LMCA) disease. However, because of marked advancements in the techniques of percutaneous coronary intervention (PCI) with stenting and $\mathrm{CABG}$ and adjunctive pharmacologic therapy, reevaluation and review of current indications for optimal revascularization therapy for LMCA disease are required to determine the standard of care for these patients. The available current evidence suggests that the composite outcome of death, myocardial infarction and stroke is similar in patients with LMCA disease who are treated with either $\mathrm{PCl}$ with stenting or $\mathrm{CABG}$, the only difference being the rate of repeat revascularization. Cumulative and emerging data from several extensive registries and a large clinical trial may have prompted many interventional cardiologists to select $\mathrm{PCl}$ with stenting as an alternative revascularization strategy for such patients. In addition, these data not only may change future guidelines, but support the need for prospective, large randomized trials comparing the 2 revascularization treatments. Finally, this evidence will change the current clinical practice of revascularization strategy for unprotected LMCA disease. (Circ J 2011; 75: 749-755)
\end{abstract}

Key Words: Bypass surgery; Left main coronary disease; Stents

$\mathbf{T}$ he standard revascularization choice for unprotected left main coronary artery (LMCA) disease is coronary-artery bypass grafting (CABG), based on the documented efficacy and survival advantage of CABG in reference to medical therapy since the 1970s. ${ }^{1,2}$ However, because of the anatomically easy accessibility and relatively large caliber of the LMCA, percutaneous coronary intervention (PCI) for LMCA disease has been attractive to the interventional cardiologist. Technical advances in both PCI and stent technology have emboldened the physician to test the feasibility of LMCA intervention and, coupled with the widespread availability of drug-eluting stents (DES), has led to a reevaluation of the role of PCI as a viable alternative treatment for unprotected LMCA disease. ${ }^{3}$

However, there are limited data regarding the long-term outcomes of PCI and limited numbers of well-conducted, large randomized trials comparing $\mathrm{PCI}$ and $\mathrm{CABG}$ for such patients. We therefore reviewed the current evidence and future prospects of PCI with stenting of the LMCA and the alternative role of PCI in reference to standard CABG for patients with LMCA disease.

\section{Outcomes of PCI With Stenting}

Over the past years, using PCI with bare metal stents (BMS), LMCA intervention has shown its feasibility and acceptable short- and mid-term outcomes. Due to marked improvement in the efficacy of DES compared to BMS, many experienced interventional cardiologists currently perform PCI with DES for patients with unprotected LMCA disease. Several observational studies, although limited by their non-randomized nature, small number of patients, and short follow-up periods, have shown promising outcomes for PCI using DES compared with BMS..$^{47}$ However, there remains some clinical uncertainty regarding the optimal stent type for use in unprotected LMCA disease. The use of DES in left main (LM) disease has been regarded as an off-label application and adverse events associated with DES has been pronounced, in particular late stent thrombosis. Recently, a well-conducted, large meta-analysis comparing outcomes for DES and BMS afterPCI for unprotected LMCA disease was reported. ${ }^{8}$ A total of 44 studies and 10,342 patients who received a DES or BMS were analyzed. The respective (DES vs. BMS) cumulative event rates at 3 years were $8.8 \%$ and $12.7 \%$ for death, $4.0 \%$ and $3.4 \%$ for MI, $8.0 \%$ and $16.4 \%$ for target vessel revascularization/target lesion revascularization (TVR/TLR), and $21.4 \%$ and $31.6 \%$ for major adverse cardiovascular events (MACE). Adjusted outcomes at 3 years favored DES (Figure).

\section{Ostial and/or Shaft Disease}

The feasibility and success of PCI with stent implantation for LMCA disease require careful evaluation of the lesion's com-

Received February 22, 2011; accepted February 23, 2011; released online March 10, 2011

Division of Cardiology, University of Ulsan College of Medicine, Asan Medical Center, Seoul, Korea

Mailing address: Seung-Jung Park, MD, PhD, Division of Cardiology, University of Ulsan College of Medicine, Asan Medical Center,

388-1 Poongnap-dong, Songpa-gu, Seoul, 138-736, Korea. E-mail: sjpark@amc.seoul.kr

ISSN-1346-9843 doi:10.1253/circj.CJ-11-0217

All rights are reserved to the Japanese Circulation Society. For permissions, please e-mail: cj@j-circ.or.jp 


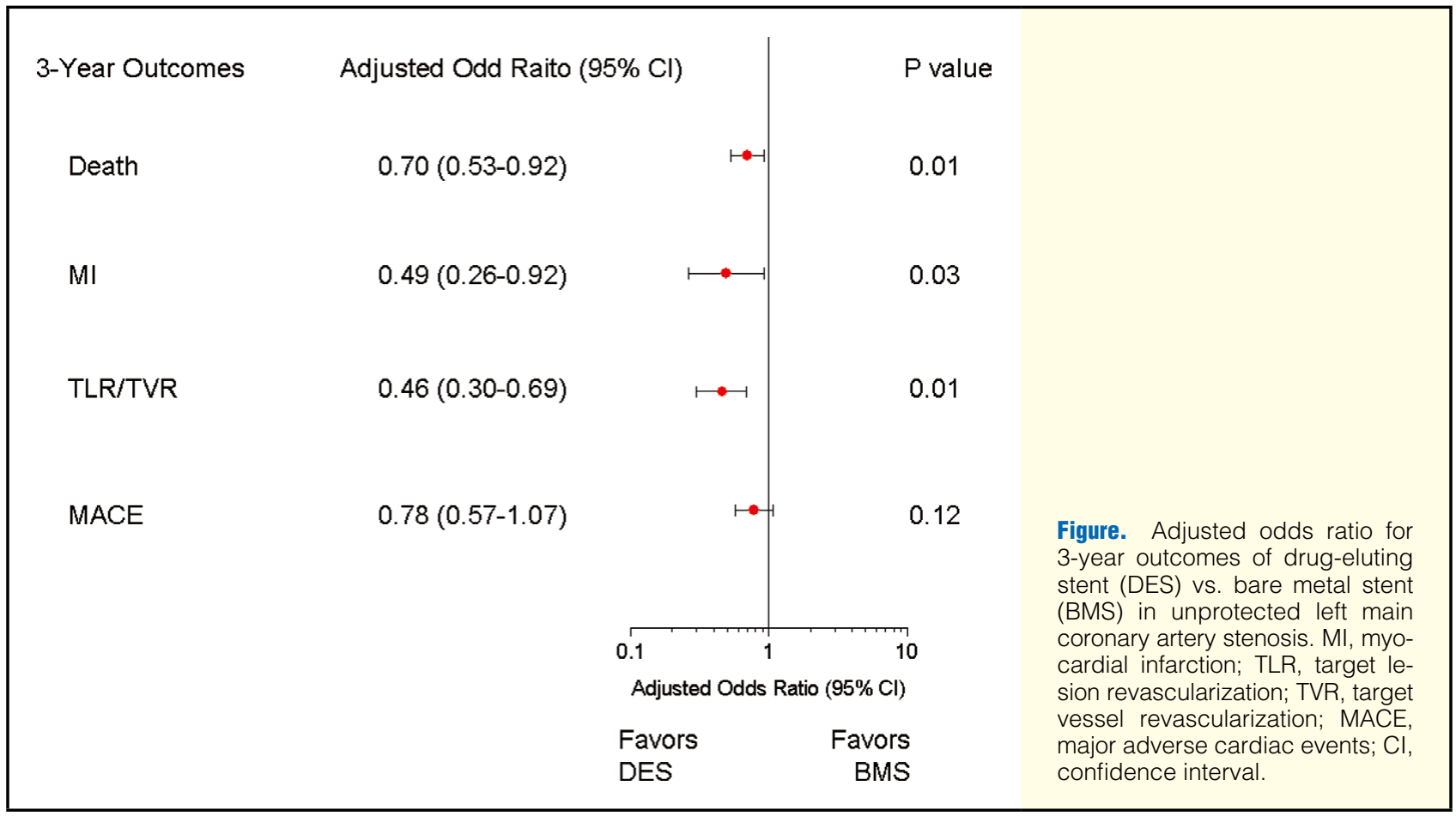

plexity. The probability of procedural success requires consideration of whether the atherosclerotic coronary plaque involves the ostium and/or shaft of the LMCA, or the length of the LM trunk and whether obstructing plaque involves the distal bifurcation with or without extension into the left anterior descending (LAD) or circumflex artery (LCX). With the marked reduction in restenosis with DES and the large caliber and easy accessibility of most LM arteries, which could attenuate this benefit, ostial/shaft disease might be the attractive target for LMCA intervention. A multicenter observational study demonstrated favorable long-term outcomes with DES; procedural success was achieved in $99 \%$ of patients, no case of in-hospital Q-wave MI or death, mean late lumen loss of $0.01 \mathrm{~mm}$ and restenosis of $0.9 \%$ at angiographic follow-up, and favorable long-term clinical outcomes (3.4\% cumulative mortality and $4.7 \%$ TVR at median 2.4 years). ${ }^{9}$

\section{Distal Bifurcation Disease}

The distal bifurcation is involved in more than half of all patients (60-90\%) with LMCA disease. Several studies suggest that results are less favorable when distal LMCA lesions are treated by a 2-stent approach compared with 1-stent approach. ${ }^{10,11}$ The TLR rate is relatively low $(<5 \%)$ with a 1 -stent approach, even for distal LMCA lesions, and is nearly equivalent to results obtained with DES for ostial or midLM lesions. ${ }^{4-6}$ However, patients with distal LMCA lesions treated with 2-stent techniques have shown a TLR rate as high as $25 \%$, with restenosis confined mainly to the LCX ostium. A recent large observation study evaluated the impact of distal bifurcation involvement and the role of 1 vs. 2 stents for 1,111 consecutive patients receiving DES for unprotected LMCA disease. ${ }^{12}$ Compared with ostial or midshaft lesions, the distal LM bifurcation was associated with a $50 \%$ excess risk of adverse outcomes, which was mainly driven by bifurcation lesions that were treated with complex stenting, as no difference in outcomes was observed between patients with 1-stent bifurcation treatment and those with ostial or midshaft LMCA lesions.

\section{Safety of LM Stenting}

Concerns have been raised regarding the long-term safety of DES, with particular regard to late stent thrombosis and late mortality. ${ }^{13-15}$ Increasing concern over stent thrombosis, which may have more catastrophic consequences that most likely would result in sudden death in patients who received unprotected LMCA stenting, and a lack of long-term clinical data, have hampered the widespread use of PCI with DES as an alternative to CABG. However, recent data alleviate concerns about the safety of PCI with DES for the treatment of unprotected LMCA disease. ${ }^{16-19}$ Currently, reported rates of stent thrombosis among several large observational studies in patients who received DES implantation for unprotected LMCA disease range between $1 \%$ and $2 \%$ within $1-3$ years. It provides further evidence that LMCA PCI with DES results in lower or, at worst, similar rates of stent thrombosis than rates reported among patients with other coronary lesions in routine clinical practice. In addition, there are very limited data regarding the performance of second- and third-generation DES for unprotected LMCA stenting. Since secondgeneration DES show superior safety and efficacy to firstgeneration DES, ${ }^{20,21}$ the relative long-term benefits of the new-generation DES compared to first-generation DES or CABG should be reassessed soon for optimal LMCA revascularization.

\section{Technical Aspect of PCI With Stenting}

\section{FFR-Guided Decision Making}

Recent studies have suggested that fractional flow reserve (FFR)-guided PCI is associated with reduced major adverse cardiac events in patients with multivessel coronary artery disease (CAD). ${ }^{22}$ Previous studies have demonstrated that 
FFR $>0.75-0.80$ was a strong predictor of favorable clinical outcomes in patients with intermediate LM disease. ${ }^{23-25}$ Based on an FFR $<0.75$ vs. $\geq 0.75$, Jasti et al reported that 38 -month survival rates were $100 \%$ vs. $100 \%$ and event-free survival estimates were $100 \%$ vs. $90 \%$, respectively (all, $\mathrm{P}>0.05$ ), ${ }^{23}$ When treatment strategy of equivocal LM stenosis was determined by FFR $<0.80$ (bypass surgery) vs. $\geq 0.80$ (medical therapy), 5-year survival estimates were similar between surgical and nonsurgical groups $(85.4 \%$ vs. $89.8 \%, \mathrm{P}=0.48)$ as were the 5-year event-free survival estimates $(74.2 \%$ vs. $82.8 \%, \mathrm{P}=$ $0.50) .25$ Thus, FFR measurement is appropriate for identifying patients with intermediate LM stenosis in whom deferral of revascularization is associated with excellent survival and low event rates.

In addition, because angiographic assessment of LM stenosis severity is not accurate, there have been attempts to find intravascular ultrasound (IVUS) measurements that correspond to the functional significance and clinical outcomes and to integrate morphologic, physiologic, and long-term follow-up data. The suggested minimal lumen area (MLA) cut-point has varied from 5.9 to $9.6 \mathrm{~mm}^{2}$ for identifying significant LM disease, so the optimal cut-off value and its accuracy remains debatable. Therefore, new studies to determine the best IVUS criteria for predicting the physiologic significance of intermediate LM lesions using FFR as the standard are also required.

\section{IVUS-Guided Optimization}

Because the conventional coronary angiogram is only a lumenogram providing information on lumen diameter but yielding little insight into lesion or plaque characteristics, exact evaluation of LMCA disease is sometimes difficult if there are peculiar anatomic and hemodynamic factors such as large size, a short normal reference segment, overlapping of major vessels, aortic cusp opacification, streaming of contrast agent, and various angulations.

During LMCA stenting, especially PCI for distal LMCA bifurcation lesions, IVUS-assisted PCI might be very helpful for measuring the degree of stenosis, plaque characteristics, and anatomic configuration (with delineation of major side branches) in order to select the appropriate diameter and length of the stent, as well as the optimal stenting strategy, and to detect post-procedural stent underexpansion, incomplete lesion coverage, residual plaque, and stent inapposition. A multicenter observational study suggested that elective DES implantation with IVUS guidance might reduce the long-term mortality rate for unprotected LMCA as compared with conventional angiography-alone guidance. ${ }^{26}$

In addition, there are limited data on the pre- and postprocedural IVUS predictors of adverse events after DES implantation into distal LM bifurcation stenoses. Kang et $\mathrm{al}^{27}$ evaluated a total of 168 patients with distal LM bifurcation stenting with DES. Their independent predictors for poststenting minimal stent area (MSA) within the distal portion of the LM above the LAD carina were pre-procedural lumen area of the LAD carina $(\beta=0.253,95 \%$ confidence interval $[\mathrm{CI}] 0.10-0.36, \mathrm{P}=0.001)$ and pre-procedural MLA within the polygon of confluence $(\mathrm{POC}=$ confluent zone of $\mathrm{LAD}$ and LCX) $(\beta=0.205,95 \%$ CI $0.04-0.23, \mathrm{P}=0.008)$. On their multivariable Cox model, female gender (adjusted hazard ratio [HR] 2.56, 95\%CI 1.173-5.594, $\mathrm{P}=0.018)$ and pre-procedural MLA within the POC (adjusted HR 0.829, 95\% CI 0.708 $0.971, \mathrm{P}=0.020$ ) were the independent predictors for the occurrence of events at 3-year follow-up. Thus, as assessed by simple LAD pullback, the pre-procedural MLA within the
POC was a surrogate for the overall severity of LM bifurcation disease, contributed to post-stenting MSA within the distal segment of the LM bifurcation, and was a predictor of long-term clinical outcomes during follow-up.

\section{Optimal Management of In-Stent Restenosis After LM Stenting}

Few data on the clinical course and management of patients experiencing restenosis after DES treatment for unprotected LMCA disease have appeared. FAILS (Failure in Left Main Study $)^{28}$ evaluated 70 patients with post-DES restenosis after LMCA stenting. Among them, 59 (84.3\%) were treated with repeated PCI (DES, BMS, or balloon angioplasty only), whereas $7(10 \%)$ patients underwent $\mathrm{CABG}$, and $4(5.7 \%)$ were treated medically. During follow-up of 27 months, the cumulative incidence of long-term MACE (death, MI, TLR) was $50 \%$ in the medical group, $25 \%$ in the PCI group, and $14 \%$ in the $\mathrm{CABG}$ group. Lee et $\mathrm{al}^{29}$ also evaluated 71 cases of in-stent restenosis (ISR; 17.6\%) among 402 patient who received DES implantation for LMCA disease; 57 cases were focal-type and 14 were diffuse-type ISR. Of the patients, $40(56.3 \%)$ underwent repeated PCI, 10 (14.1\%) underwent bypass surgery, and $21(29.6 \%)$ were treated medically. During long-term follow-up (median 31.7 months), the incidence of MACE was $14.4 \%$ in the medical group, $13.6 \%$ in the PCI group, and $10.0 \%$ in the bypass surgery group $(\mathrm{P}=0.91)$. These data suggested that the long-term clinical prognosis of patients with DES-ISR associated with LMCA stenting was benign, regardless of treatment type, which depended mainly on physician discretion.

\section{Efficacy and Safety of PCI vs. CABG}

CABG has usually been recommended for LM disease in symptomatic patients. Surgical approaches have a distinct advantage, because bypass grafts are placed distally to the LAD and LCX, meaning anatomic complexity and the location of the LM coronary lesion can be ignored, and complete revascularization is easily accomplished. Although the benefits of CABG are well known, the procedure results in a large portion of myocardium being potentially supplied solely by a venous graft with a limited duration of patency. By contrast, PCI of LMCA lesions is relatively technically feasible due to the large vessel caliber and its easy accessibility, and successful LMCA stenting would ensure complete arterial revascularization of the entire coronary arterial vasculature. ${ }^{30}$

Table 1 summarizes key observational studies, meta-analyses, and randomized trials comparing PCI with DES with CABG.

\section{Registry Data}

Although several studies have reported on the mid-term safety and feasibility of stenting in LMCA disease, the long-term benefits of PCI compared with bypass surgery are less clear, in part because they have been evaluated less extensively. Several small observational studies have compared PCI with stenting of unprotected LMCA to CABG. ${ }^{31-35}$ The early clinical events of LM stenting are similar or superior to those of bypass surgery because of the significant increase in periprocedural $\mathrm{MI}^{31}$ or cerebrovascular events ${ }^{32}$ in the CABG patients. Longer-term mortality up to approximately 1 year was similar in the PCI and the CABG groups. However, the risk of TVR was consistently higher with PCI than with CABG. 


\begin{tabular}{|c|c|c|c|c|c|}
\hline Design/Study & $\begin{array}{l}\text { DES } \\
\text { (n) }\end{array}$ & $\begin{array}{c}\text { CABG } \\
\text { (n) }\end{array}$ & Follow-up & $\begin{array}{l}\text { Adjusted risk } \\
\text { for death }\end{array}$ & $\begin{array}{l}\text { Adjusted risk } \\
\text { for TVR/TLR }\end{array}$ \\
\hline \multicolumn{6}{|l|}{ Nonrandomized study } \\
\hline MAIN-COMPARE ${ }^{36}$ & 784 & 690 & 5 years & HR 1.00 (0.73-0.37), $P=0.99$ & HR 6.45 (3.75-11.09), $P=0.34$ \\
\hline Lee et $\mathrm{al}^{32}$ & 153 & 50 & 6.7 months & $\begin{array}{l}4 \% \text { for } D E S, 13 \% \text { for } C A B G \\
P=0.18\end{array}$ & $\begin{array}{l}7 \% \text { for } D E S, 1 \% \text { for } C A B G \\
P=0.22\end{array}$ \\
\hline Chieffo $^{6}$ & 107 & 142 & 1 year & OR $0.33(0.06-1.40), P=0.17$ & OR 4.22 (1.49-14.55), $P=0.005$ \\
\hline Palmerini et $\mathrm{al}^{33}$ & 94 & 154 & 1.2 years & HR 0.99 (0.47-2.07), $P=0.97$ & $\begin{array}{l}25.5 \% \text { for } \mathrm{PCl}, 2.6 \% \text { for } \mathrm{CABG} \\
\mathrm{P}=0.0001\end{array}$ \\
\hline Sanmartin et al ${ }^{34}$ & 96 & 245 & 1 year & $\begin{array}{l}5.2 \% \text { for } \mathrm{DES}, 8.4 \% \text { for } \mathrm{CABG} \text {, } \\
P=0.34\end{array}$ & $\begin{array}{l}5.2 \% \text { for } \mathrm{DES}, 0.8 \% \text { for } \mathrm{CABG} \\
P=0.004\end{array}$ \\
\hline \multicolumn{6}{|l|}{ Meta-analysis } \\
\hline Takagi et al ${ }^{42}$ & 1,006 & 1,175 & 3 months to 3 years & OR 0.99 (0.69-1.43), $P=0.97$ & OR 5.05 (3.07-8.30), P<0.001 \\
\hline Lee et $\mathrm{al}^{43}$ & 1,236 & 1,669 & 1 year & OR $1.12(0.80-1.56)$ & OR $0.44(0.32-0.59)$ \\
\hline \multicolumn{6}{|c|}{ Randomized controlled trial } \\
\hline Buzman & 52 & 53 & 1 year & $\begin{array}{l}\text { Survival: } 98.1 \% \text { for } \mathrm{PCl} / 92.5 \% \\
\text { for CABG, } \mathrm{P}=0.37\end{array}$ & $\begin{array}{l}9.7 \% \text { for } \mathrm{PCl}, 9.4 \% \text { for } \mathrm{CABG} \text {, } \\
\mathrm{P}=0.97\end{array}$ \\
\hline SYNTAX substudy ${ }^{38}$ & 357 & 348 & 1 year & $\begin{array}{l}4.4 \% \text { for } \mathrm{DES}, 4.2 \% \text { for } \mathrm{CABG} \text {, } \\
P=0.88\end{array}$ & $\begin{array}{l}11.8 \% \text { for } \mathrm{DES}, 6.5 \% \text { for } \mathrm{CABG} \text {, } \\
P=0.02\end{array}$ \\
\hline Boudriot et al 40 & 100 & 101 & 1 year & $2.0 \%$ for $\mathrm{DES}, 5.0 \%$ for $\mathrm{CABG}$ & $14.0 \%$ for $\mathrm{DES}, 5.9 \%$ for $\mathrm{CABG}$ \\
\hline
\end{tabular}

Data in parentheses are $95 \%$ confidence interval.

DES, drug-eluting stent; CABG, coronary-artery bypass grafting; TVR, target vessel revascularization; TLR, target lesion revascularization; $\mathrm{HR}$, hazard ratio; OR, odds ratio; $\mathrm{PCl}$, percutaneous coronary intervention.

The MAIN-COMPARE registry is a large, multicenter, long-term follow-up study comparing PCI with BMS or DES and $\mathrm{CABG}$ for unprotected LMCA disease. ${ }^{19}$ This registry included 2,240 patients with unprotected LMCA disease who underwent stenting (BMS 318; DES 784) or CABG $(1,138)$ at 12 major cardiac centers in Korea. First report at 3 years after propensity-matching showed that the risks of death and the composite of death, Q-wave MI, or stroke were similar in the PCI and CABG groups and these results were consistent when either BMS or DES was compared with concurrent CABG. However, the rate of TVR was significantly lower in the CABG group than in the PCI group with hazard ratios varying by the type of stent. DES recipients were almost 6-fold more likely, and BMS recipients almost 10-fold more likely, to require revascularization, compared to those who underwent surgery. Recently, more long-term, 5-year results of the MAIN-COMPARE registry were reported. ${ }^{36}$ After adjustment for differences in baseline risk factors with the inverse probability of treatment weighting, the 5-year risk of death (HR: 1.13 ; 95\% CI: $0.88-1.44, \mathrm{P}=0.35$ ) and the combined risk of death, Q-wave MI, or stroke (HR: 1.07; 95\%CI: $0.84-1.37, \mathrm{P}=0.59$ ) were not significantly different for patients undergoing stenting vs. CABG. The risk of TVR was significantly higher in the stenting group than in the $\mathrm{CABG}$ group (HR: 5.11; 95\%CI: 3.52-7.42, $\mathrm{P}=0.001$ ).

\section{Randomized Clinical Trial Data}

The evidence from randomized trials comparing CABG and PCI in LMCA disease is limited. Although assessment of pure treatment effects among 2 primary revascularization methods can be achieved from randomized clinical trials, the use of composite endpoints, small numbers of patients, and the limited duration of follow-up have biased the studies' findings. There is also bias to entry into the trial, which is a major limitation after the trial is over and the physician needs to extrapolate the data to clinical practice.

The LeMANS trial was the first randomized comparison of PCI with stenting (52 patients) and CABG (53 patients) for treatment of unprotected LMCA stenosis, with or without multivessel CAD. ${ }^{37}$ DES were placed in $35 \%$ of PCI patients and left internal mammary artery grafts were used in $72 \%$ of CABG patients. At 1 year, the primary endpoint of absolute change in left ventricular ejection fraction was significantly greater in the PCI than in the CABG group $(3.3 \pm 6.7 \%$ vs. $0.5 \pm 0.8 \% ; \mathrm{P}=0.047$ ), whereas the secondary endpoints, survival and major adverse cardiac or cerebrovascular events (MACCE), were comparable in the 2 groups. However, this first trial is limited by the small number of patients and the nonspecific and inconclusive primary endpoint chosen to evaluate treatment effects.

In subgroup LMCA analysis from the SYNTAX trial, ${ }^{38}$ PCI demonstrated 12-month rates of MACCE, death, MI, or stroke, equivalent to those seen after $\mathrm{CABG}$, but a higher rate of TVR was observed in the DES arm, which was offset by an increase in the rate of stroke in the surgical arm. A post hoc analysis of the patients with LMCA disease found that those who also had 2- or 3-vessel disease had, after PCI, a significantly higher rate of the primary outcome than those with LMCA disease alone or in combination with 1-vessel disease (1VD) (19.8\% and $19.3 \%$ vs. $7.1 \%$ and $7.5 \%$, respectively). These overall findings were consistent up to 3 years of clinical follow-up. ${ }^{39}$

Recently, Boudriot et al reported the results of randomized trial comparing sirolimus-eluting stenting $(n=100)$ with CABG $(n=101)$ for patients with unprotected LMCA disease. ${ }^{40}$ The primary end point was noninferiority in free of MACE (cardiac death, MI, and TVR) at 12 months. At 1 year, the incidence of the primary end point was $13.9 \%$ in the CABG group and $19.0 \%$ in the PCI group $(\mathrm{P}=0.19$ for noninferiority). The combined rates for death and MI were similar (7.9\% in CABG vs. $5.0 \%$ in PCI), but repeat revascularization was significantly higher in the PCI group (14.0\% vs. $5.9 \%$ of CABG).

Two large randomized trials, the PRECOMBAT (Randomized Comparison of Bypass Surgery Versus Angioplasty Using Sirolimus-Eluting Stent in Patients With Left Main 


\begin{tabular}{|c|c|c|}
\hline Guideline & Past recommendation & Current recommendation \\
\hline ACC/AHA Guideline & $\begin{array}{l}-2005 \text { PCI Guideline } \rightarrow \text { Class III } \\
\text { PCI is not recommended in patients with LM disease } \\
\text { and eligibility for CABG (Level of Evidence: C) }\end{array}$ & $\begin{array}{l}-2009 \text { PCI Guideline } \rightarrow \text { Class Ilb } \\
\text { PCI of the LM coronary artery with stents as an alternative to } \\
\text { CABG may be considered in patients with anatomic conditions } \\
\text { that are associated with a low risk of PCI procedural compli- } \\
\text { cations and clinical conditions that predict an increased risk } \\
\text { of adverse surgical outcomes (Level of Evidence: } \mathrm{B} \text { ) }\end{array}$ \\
\hline ESC Guideline & $\begin{array}{l}\text { - } 2005 \text { PCl Guideline } \rightarrow \text { Class Ilb C } \\
\text { Stenting for unprotected LM disease should only be } \\
\text { considered in the absence of other revascularization } \\
\text { options }\end{array}$ & $\begin{array}{l}\text { - } 2010 \text { PCI Guideline } \rightarrow \text { Class Ila B-III B } \\
\text { LM (isolated or } 1 V D \text {, ostium/shaft): Ila B, LM (isolated or 1VD, } \\
\text { distal bifurcation): Illb B, LM +2VD or 3VD, SYNTAX score } \\
\leq 32 \text { : Ilb B, LM + 2VD or 3VD, SYNTAX score }>33 \text { : III B }\end{array}$ \\
\hline
\end{tabular}

ACC/AHA, American Heart Association/American College of Cardiology; ESC, European Society of Cardiology; PCl, percutaneous coronary intervention; CABG, coronary-artery bypass grafting; $L M$, left main; VD, vessel disease.

Coronary Artery Disease) and EXCEL (Evaluation of Xience Prime versus Coronary Artery Bypass Surgery for Effectiveness of Left Main Revascularization), might provide more confirmatory information regarding the relative efficacy and safety of PCI with DES and CABG for patients with unprotected LMCA disease.

\section{Meta-Analysis}

A systemic review conducted by Taggart et al suggested that early (in-hospital, to 30 days) and longer-term (1-2 year) mortality rates were better after CABG (early, $2-4 \%$, average 3\%; late, 5-6\%, average 5\%) than PCI with BMS (early, $0-14 \%$, average $6 \%$; late, $3-31 \%$, average $17 \%$ ) or DES (early, $0-10 \%$, average $2 \%$; late, $0-14 \%$, average $7 \%$ ). ${ }^{41}$

Takagi et al reported a meta-analysis of 2,181 patients with unprotected LMCA disease who underwent stenting $(\mathrm{n}=1,006)$ or CABG $(\mathrm{n}=1,175)$ in 6 studies $(1$ randomized and 5 observational studies). ${ }^{42}$ Analytic results demonstrated no significant difference in death rate between stenting and CABG (odds ratio [OR] 0.99, 95\%CI 0.69-1.43, P=0.97), but a statistically significant increase in repeated revascularization with stenting (OR 5.05, 95\% CI 3.07-8.30, P<0.001), and a statistically nonsignificant benefit of stenting relative to CABG (OR 0.68, 95\%CI 0.32-1.46, $\mathrm{P}=0.32$ ).

Recently, Lee et al also performed a similar meta-analysis (2,905 patients from 8 clinical studies: 2 randomized trials and 6 observational studies) comparing $\mathrm{CABG}$ and PCI with DES for unprotected LMCA disease. ${ }^{43}$ At 1-year follow-up, there was no significant difference between the CABG and DES groups in the risk for death (OR 1.12, 95\%CI 0.80-1.56) or the composite endpoint of death, MI, or stroke (OR 1.25, 95\% CI 0.86-1.82). The risk for TVR was significantly lower in the CABG group as compared to the DES group (OR 0.44, 95\%CI 0.32-0.59). However, these results of systemic review and meta-analysis should be interpreted with caution and regarded as only exploratory findings, given the limited number of patients, the selection or publication bias in the literature reviewed, and caveats on the internal validity of the included clinical studies.

\section{Very-Long-Term Clinical Outcomes}

Several reports have shown the successful use of coronary stenting compared with $\mathrm{CABG}$ in patients with unprotected LMCA disease. However, there are currently limited data available on the comparative outcomes after PCI or CABG for LMCA disease with follow-up durations of 5-10 years. Whether or not the results achieved with coronary stenting would be stable for $5-10$ years remains to be determined in unprotected LMCA disease. The ASAN-MAIN (ASAN
Medical Center-Left MAIN Revascularization) registry is the longest follow-up study, reporting 10-year results of BMS and 5-year results of DES as compared to concurrent CABG. ${ }^{44}$ In the 10-year follow-up cohort of BMS and concurrent CABG, the adjusted risks of death (HR $0.81 ; 95 \%$ CI $0.44-$ $1.50 ; \mathrm{P}=0.50$ ) and the composite of death, Q-wave MI, or stroke (HR 0.92; 95\%CI 0.55-1.53; $\mathrm{P}=0.74$ ) were similar between the 2 groups. The rate of TVR was significantly higher in the BMS group (HR 10.34; 95\% CI 4.61-23.18; $\mathrm{P}=0.001$ ). In the 5-year follow-up cohort of DES and concurrent $\mathrm{CABG}$, there was no significant difference in the adjusted risk of death (HR 0.83; 95\% CI 0.34-2.07; $\mathrm{P}=0.70$ ) or the risk of the composite outcome (HR 0.91 ; 95\%CI 0.451.83; $\mathrm{P}=0.79)$. The rates of TVR were also higher in the DES group than the CABG group (HR 6.22; 95\%CI 2.26-17.14; $\mathrm{P}=0.001$ ).

\section{Current Changes to ACC/AHA and ESC Guidelines}

The American Heart Association/American College of Cardiology PCI guideline has recently been updated to reflect increasing off-label experience with stenting and clinical studies (particularly the SYNTAX trial) and has led to a revision in treatment guidelines, with PCI now receiving a class IIb indication for the treatment of LMCA stenosis. ${ }^{45}$ It is likely that further discussion will ensue about whether the current knowledge basis for LMCA stenting justifies the IIa rather than a IIb recommendation.

Recent guideline from the European Society of Cardiology (ESC) and the European Association for Cardio-Thoracic Surgery (EACTS) also reported their indications of PCI relative to CABG for myocardial revascularization of LMCA disease: (1) isolated or $1 \mathrm{VD}$, ostium/shaft; class IIa B, (2) isolated or 1VD, distal bifurcation; class IIb B, (3) LM+2- or 3 -vessel disease, SYNTAX score $\leq 32$; class IIb B, (4) LM+ 2- or 3-vessel disease, SYNTAX score $\geq 33$; class III B. ${ }^{46}$

Past and recent updated guidelines of PCI for unprotected LMCA disease are summarized in Table 2.

\section{Conclusions: LM Stenting Now and in the Future}

Current evidence from clinical trials and extensive off-label experience indicates that stenting yields mortality and morbidity rates that compare favorably with $\mathrm{CABG}$, updating the current guidelines for LMCA revascularization, and might have prompted many interventional cardiologists to choose PCI with DES as a good treatment option for patients with LMCA disease. Large randomized clinical trials with longterm follow-up, such as the PRECOMBAT and EXCEL trials, can provide more confirmation. An integrated approach that 
combines more advanced devices with specialized techniques, adjunctive physiologic and imaging support, and adjunctive pharmacologic agents has greatly improved PCI success rates and long-term clinical outcomes for these complex lesions.

\section{Disclosures}

Dr S.-J. Park has received consulting fees from Cordis, lecture fees from Abott, Cordis, Medtronic, and Boston Scientific, and research grant support from Cordis and Medtronic. Dr D.-W. Park reports lecture fees from Cordis and Medtronic.

Both authors have read the manuscript and agree with the contents.

\section{References}

1. Chaitman BR, Fisher LD, Bourassa MG, Davis K, Rogers WJ, Maynard C, et al. Effect of coronary bypass surgery on survival patterns in subsets of patients with left main coronary artery disease: Report of the Collaborative Study in Coronary Artery Surgery (CASS). Am J Cardiol 1981; 48: 765-777.

2. Takaro T, Peduzzi P, Detre KM, Hultgren HN, Murphy ML, van der Bel-Kahn J, et al. Survival in subgroups of patients with left main coronary artery disease: Veterans Administration Cooperative Study of Surgery for Coronary Arterial Occlusive Disease. Circulation 1982; 66: $14-22$

3. Park SJ, Park DW. Percutaneous coronary intervention with stent implantation versus coronary artery bypass surgery for treatment of left main coronary artery disease: Is it time to change guidelines? Circ Cardiovasc Interv 2009; 2: 59-68.

4. Park SJ, Kim YH, Lee BK, Lee SW, Lee CW, Hong MK, et al. Sirolimus-eluting stent implantation for unprotected left main coronary artery stenosis: Comparison with bare metal stent implantation. J Am Coll Cardiol 2005; 45: 351-356.

5. Valgimigli M, van Mieghem CA, Ong AT, Aoki J, Granillo GA, McFadden EP, et al. Short- and long-term clinical outcome after drug-eluting stent implantation for the percutaneous treatment of left main coronary artery disease: Insights from the Rapamycin-Eluting and Taxus Stent Evaluated At Rotterdam Cardiology Hospital registries (RESEARCH and T-SEARCH). Circulation 2005; 111: 1383 1389.

6. Chieffo A, Stankovic G, Bonizzoni E, Tsagalou E, Iakovou I, Montorfano M, et al. Early and mid-term results of drug-eluting stent implantation in unprotected left main. Circulation 2005; 111: $791-795$.

7. Hsueh SK, Wu CJ, Fang HY, Hsieh YK, Fang CY, Chen CJ, et al. Comparison of drug-eluting stent with bare metal stent for distal de novo unprotected left main coronary artery stenosis. Circ J 2011; 75: $290-298$.

8. Pandya SB, Kim YH, Meyers SN, Davidson CJ, Flaherty JD, Park DW, et al. Drug-eluting versus bare-metal stents in unprotected left main coronary artery stenosis a meta-analysis. JACC Cardiovasc Interv 2010; 3: 602-611.

9. Chieffo A, Park SJ, Valgimigli M, Kim YH, Daemen J, Sheiban I, et al. Favorable long-term outcome after drug-eluting stent implantation in nonbifurcation lesions that involve unprotected left main coronary artery: A multicenter registry. Circulation 2007; 116: $158-162$

10. Kim YH, Park SW, Hong MK, Park DW, Park KM, Lee BK, et al. Comparison of simple and complex stenting techniques in the treatment of unprotected left main coronary artery bifurcation stenosis. Am J Cardiol 2006; 97: 1597-1601.

11. Valgimigli M, Malagutti P, Rodriguez Granillo GA, Tsuchida K, Garcia-Garcia HM, van Mieghem CA, et al. Single-vessel versus bifurcation stenting for the treatment of distal left main coronary artery disease in the drug-eluting stenting era: Clinical and angiographic insights into the Rapamycin-Eluting Stent Evaluated at Rotterdam Cardiology Hospital (RESEARCH) and Taxus-Stent Evaluated at Rotterdam Cardiology Hospital (T-SEARCH) registries. Am Heart J 2006; 152: 896-902.

12. Palmerini T, Sangiorgi D, Marzocchi A, Tamburino C, Sheiban I, Margheri M, et al. Ostial and midshaft lesions vs. bifurcation lesions in 1111 patients with unprotected left main coronary artery stenosis treated with drug-eluting stents: Results of the survey from the Italian Society of Invasive Cardiology. Eur Heart J 2009; 30: 2087-2094.

13. Lagerqvist B, James SK, Stenestrand U, Lindback J, Nilsson T, Wallentin L. Long-term outcomes with drug-eluting stents versus bare-metal stents in Sweden. N Engl J Med 2007; 356: 1009-1019.

14. Stone GW, Moses JW, Ellis SG, Schofer J, Dawkins KD, Morice
MC, et al. Safety and efficacy of sirolimus- and paclitaxel-eluting coronary stents. N Engl J Med 2007; 356: 998-1008.

15. Mauri L, Hsieh WH, Massaro JM, Ho KKL, D' Agostino R, Cutlip DE. Stent thrombosis in randomized clinical trials of drug-eluting stents. N Engl J Med 2007; 356: 1020-1029.

16. Chieffo A, Park SJ, Meliga E, Sheiban I, Lee MS, Latib A, et al. Late and very late stent thrombosis following drug-eluting stent implantation in unprotected left main coronary artery: A multicentre registry. Eur Heart J 2008; 29: 22108-2115.

17. Meliga E, Garcia-Garcia HM, Valgimigli M, Chieffo A, BiondiZoccai G, Maree AO, et al. Longest available clinical outcomes after drug-eluting stent implantation for unprotected left main coronary artery disease: The DELFT (Drug Eluting stent for LeFT main) Registry. J Am Coll Cardiol 2008; 51: 2212-2219.

18. Mehilli J, Kastrati A, Byrne RA, Bruskina O, Iijima R, Schulz S, et al; LEFT-MAIN Intracoronary Stenting and Angiographic Results: Drug-Eluting Stents for Unprotected Coronary Left Main Lesions Study Investigators. Paclitaxel- versus sirolimus-eluting stents for unprotected left main coronary artery disease. $\mathrm{J} \mathrm{Am} \mathrm{Coll} \mathrm{Cardiol}$ 2009; 53: 1760-1768.

19. Seung KB, Park DW, Kim YH, Lee SW, Lee CW, Hong MK, et al. Stents versus coronary-artery bypass grafting for left main coronary artery disease. N Engl J Med 2008; 358: 1781-1792.

20. Kedhi E, Joesoef KS, McFadden E, Wassing J, van Mieghem C, Goedhart D, et al. Second-generation everolimus-eluting and paclitaxel-eluting stents in real-life practice (COMPARE): A randomised trial. Lancet 2010; 375: 201-209.

21. Stone GW, Rizvi A, Newman W, Mastali K, Wang JC, Caputo R, et al. Everolimus-eluting versus paclitaxel-eluting stents in coronary artery disease. $N$ Engl J Med 2010; 362: $1663-1674$.

22. Tonino PA, De Bruyne B, Pijls NH, Siebert U, Ikeno F, van't Veer $\mathrm{M}$, et al. Fractional flow reserve versus angiography for guiding percutaneous coronary intervention. N Engl J Med 2009; 360: $213-$ 224.

23. Jasti V, Ivan E, Yalamanchili V, Wongpraparut N, Leesar MA. Correlations between fractional flow reserve and intravascular ultrasound in patients with an ambiguous left main coronary artery stenosis. Circulation 2004; 110: 2831-2836.

24. Courtis J, Rodes-Cabau J, Larose E, Potvin JM, Dery JP, Larochelliere RD, et al. Usefulness of coronary fractional flow reserve measurements in guiding clinical decisions in intermediate or equivocal left main coronary stenoses. Am J Cardiol 2009; 103: 943-949.

25. Hamilos M, Muller O, Cuisset T, Ntalianis A, Chlouverakis G, Sarno G, et al. Long-term clinical outcome after fractional flow reserve-guided treatment in patients with angiographically equivocal left main coronary artery stenosis. Circulation 2009; 120: $1505-$ 1512.

26. Park SJ, Kim YH, Park DW, Lee SW, Kim WJ, Suh J, et al. Impact of intravascular ultrasound guidance on long-term mortality in stenting for unprotected left main coronary artery stenosis. Circ Cardiovasc Interv 2009; 2: 167-177.

27. Kang SJ, Mintz GS, Kim WJ, Lee JY, Park DW, Yun SC, et al. Effect of intravascular ultrasound findings on long-term repeat revascularization in patients undergoing drug-eluting stent implantation for severe unprotected left main bifurcation narrowing. Am J Cardiol 2011; 107: 367-373

28. Sheiban I, Sillano D, Biondi-Zoccai G, Chieffo A, Colombo A, Vecchio S, et al. Incidence and management of restenosis after treatment of unprotected left main disease with drug-eluting stents 70 restenotic cases from a cohort of 718 patients: FAILS (Failure in Left Main Study). J Am Coll Cardiol 2009; 54: 1131-1136.

29. Lee JY, Park DW, Kim YH, Yun SC, Kim WJ, Kang SJ, et al. Incidence, predictors, treatment, and long-term prognosis of patients with restenosis after drug-eluting stent implantation for unprotected left main coronary artery disease. J Am Coll Cardiol 2011 (in press).

30. Takagi H, Umemoto T. Drug-eluting stents vs bypass surgery for unprotected left main disease [Letter]. Circ J 2010; 74: 2244; author reply 2245 .

31. Chieffo A, Morici N, Maisano F, Bonizzoni E, Cosgrave J, Montorfano M, et al. Percutaneous treatment with drug-eluting stent implantation versus bypass surgery for unprotected left main stenosis: A single-center experience. Circulation 2006; 113: 2542-2547.

32. Lee MS, Kapoor N, Jamal F, Czer L, Aragon J, Forrester J, et al. Comparison of coronary artery bypass surgery with percutaneous coronary intervention with drug-eluting stents for unprotected left main coronary artery disease. J Am Coll Cardiol 2006; 47: 864870 .

33. Palmerini T, Marzocchi A, Marrozzini C, Ortolani P, Saia F, Savini $\mathrm{C}$, et al. Comparison between coronary angioplasty and coronary 
artery bypass surgery for the treatment of unprotected left main coronary artery stenosis (the Bologna Registry). Am J Cardiol 2006; 98: $54-59$.

34. Sanmartin M, Baz JA, Claro R, Asorey V, Duran D, Pradas G, et al. Comparison of drug-eluting stents versus surgery for unprotected left main coronary artery disease. Am J Cardiol 2007; 100: 970 973.

35. Cheng CI, Lee FY, Chang JP, Hsueh SK, Hsieh YK, Fang CY, et al. Long-term outcomes of intervention for unprotected left main coronary artery stenosis: Coronary stenting vs coronary artery bypass grafting. Circ J 2009; 73: 705-712.

36. Park DW, Seung KB, Kim YH, Lee JY, Kim WJ, Kang SJ, et al. Long-term safety and efficacy of stenting versus coronary artery bypass grafting for unprotected left main coronary artery disease: 5-year results from the MAIN-COMPARE (Revascularization for Unprotected Left Main Coronary Artery Stenosis: Comparison of Percutaneous Coronary Angioplasty Versus Surgical Revascularization) registry. J Am Coll Cardiol 2010; 56: 117-124.

37. Buszman PE, Kiesz SR, Bochenek A, Peszek-Przybyla E, Szkrobka I, Debinski M, et al. Acute and late outcomes of unprotected left main stenting in comparison with surgical revascularization. J Am Coll Cardiol 2008; 51: 538-545.

38. Morice MC, Serruys PW, Kappetein AP, Feldman TE, Stahle E, Colombo A, et al. Outcomes in patients with de novo left main disease treated with either percutaneous coronary intervention using paclitaxel-eluting stents or coronary artery bypass graft treatment in the Synergy Between Percutaneous Coronary Intervention with TAXUS and Cardiac Surgery (SYNTAX) trial. Circulation 2010; 121: $2645-2653$.

39. Serruys PW. The Synergy between Percutaneous Coronary Intervention with TAXUS and Cardiac Surgery (SYNTAX) Study: The 3-year Outcomes of the SYNTAX Trial in the Subset of Patients With Left Main Disease. In: Transcatheter Cardiovasc Ther (TCT) Meeting, 2010.

40. Boudriot E, Thiele H, Walther T, Liebetrau C, Boeckstegers P, Pohl T, et al. Randomized comparison of percutaneous coronary intervention with sirolimus-eluting stents versus coronary artery bypass grafting in unprotected left main stem stenosis. $J$ Am Coll Cardiol 2011; 57: 538-545.

41. Taggart DP, Kaul S, Boden WE, Ferguson TB Jr, Guyton RA, Mack MJ, et al. Revascularization for unprotected left main stem coronary artery stenosis stenting or surgery. $\mathrm{J} \mathrm{Am} \mathrm{Coll} \mathrm{Cardiol}$ 2008; 51: $885-892$.

42. Takagi H, Kawai N, Umemoto T. Stenting versus coronary artery bypass grafting for unprotected left main coronary artery disease: A meta-analysis of comparative studies. J Thorac Cardiovasc Sur 2009; 137: e54-e57.

43. Lee MS, Yang T, Dhoot J, Liao H. Meta-analysis of clinical studies comparing coronary artery bypass grafting with percutaneous coronary intervention and drug-eluting stents in patients with unprotected left main coronary artery narrowings. Am J Cardiol 2010; 105: $1070-1075$.

44. Park DW, Kim YH, Yun SC, Lee JY, Kim WJ, Kang SJ, et al. Long-term outcomes after stenting versus coronary artery bypass grafting for unprotected left main coronary artery disease: 10 -year results of bare-metal stents and 5-year results of drug-eluting stents from the ASAN-MAIN (ASAN Medical Center-Left MAIN Revascularization) Registry. J Am Coll Cardiol 2010; 56: 1366-1375.

45. Kushner FG, Hand M, Smith SC Jr, King SB 3rd, Anderson JL, Antman EM, et al. 2009 Focused Updates: ACC/AHA Guidelines for the Management of Patients With ST-Elevation Myocardial Infarction (updating the 2004 Guideline and 2007 Focused Update) and ACC/AHA/SCAI Guidelines on Percutaneous Coronary Intervention (updating the 2005 Guideline and 2007 Focused Update): A report of the American College of Cardiology Foundation/American Heart Association Task Force on Practice Guidelines. Circulation 2009; 120: 2271-2306.

46. Wijns W, Kolh P, Danchin N, Di Mario C, Falk V, Folliguet T, et al. Guidelines on myocardial revascularization: The Task Force on Myocardial Revascularization of the European Society of Cardiology (ESC) and the European Association for Cardio-Thoracic Surgery (EACTS). Eur Heart J 2010; 31: 2501-2555. 